\title{
The well-tempered way of transcending disciplines and solving urban problems
}

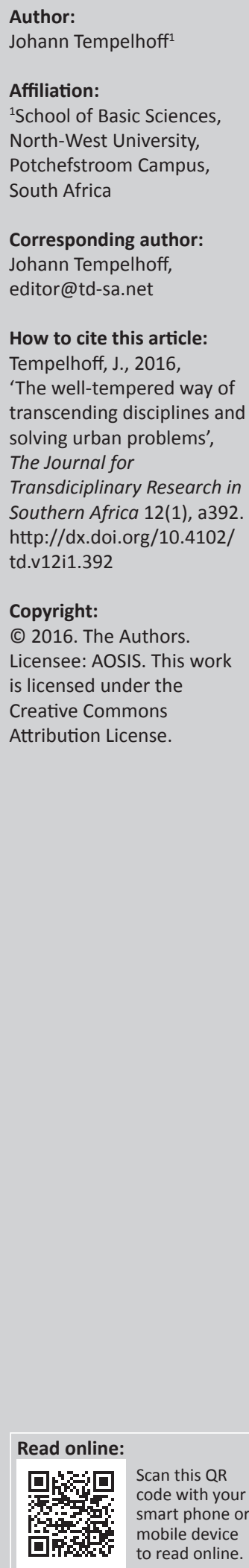

What does contemporary urban planning have in common with J.S. Bach's two booklets composed in 1722 and 1742 on the Well-Tempered Clavier? Judging from a recent publication by Jonathan F.P. Rose, the answer is: just about everything. Working from the realisation that modernist urban planning is in need of substantial revision, Rose a developer, town planner and innovative thinker on the concept of the city, has courageously opened up a different way for us to understand the need for linking urban dwellers up into communities who are able to comfortably and meaningfully experience the environments in which they live (Rose 2016).

The music of Bach was responsible in the 18th century for introducing a new system of tuning musical instruments dating back to Pythagoras ( 570 to 495 BCE). The latter, as mathematician, was responsible for a theory of notes based on 'the harmony of the spheres'. Bach, working from Zhu Zaiyu's Fusion of Music and Calendar (1580) transmitted to Western Europe by Matteo Ricci and the subsequent work of Andreas Werckmeister (1687), changed the way we today understand music. Bach's well-tempered clavier is not only exquisite and fine to listen to, but most inspiring for those who can simultaneously think and listen to music.

At a recent session of the Long Now Foundation in San Francisco, Rose discussed The well-tempered city: What modern science, ancient civilisations, and human nature teach us about the future of urban life. ${ }^{1}$ The presentation was well received by some of the leading buffs in the United States preoccupied with contemplating the past and future on time scales extending 10000 years.

Sub-Saharan Africa is currently one of the fastest urbanising continents on the globe, and many of our urban social-ecological problems stem from an apparent inability to learn from the past and integrated with our anticipation of what we need to have to move successfully from the present into the future. Rose's thinking is succinct. He writes with great clarity. Perhaps we in southern Africa can explore some current North American experiments in urban renewal, development and planning. As a planner, developer and creative thinker, Rose has worked internationally in collaboration with local authorities and not-for-profit organisations to add value to the quality of human lives in an urban environment. He is sensitive to the concept of integrated urban environment where there is space for community formations that accommodate the needs of the wealthy and the less than wealthy, as well as intellectuals and those engaged in industrial and commercial activities in our cities. Interestingly, he argues that after nature (the most complex system we know of) cities are increasingly becoming more complex. We need to comprehend and find solutions to issues of complicatedness in the world's urban spaces. The city is still a great magnet for humankind in all parts of the globe. It will remain the case for the foreseeable future. Therefore, we need to explore useful ways of cohabiting in these spaces. Rose's work is worth exploring for those of us who have an interest in wandering along the less explored transdisciplinary avenues of intellectual thought.

\section{Td and AOSIS 2016}

In reflecting on 2016 at Td The Journal for Transdisciplinary Research in Southern Africa, we are able to report that our foray into the formal publishing field of open-access publication is making good progress.

Some of our valued co-workers (authors, reviewers and editorial members) have queried the more IT-orientated character of the journal. AOSIS staffers have been most helpful in assisting both authors and reviewers if and where they experienced problems in accessing and processing material. The website (http://www.td-sa.net/) is becoming more user-friendly as we respond to user queries and suggestions.

1. See 'Seminars about long-term thinking' in The Long Now Foundation at http://longnow.org/ 
There have also been comments on the higher price of publishing. On that topic, we can say much in defence of open access publishing and the relatively small price authors pay for proper peer reviewed and accredited journal articles. What stands out in the latest edition of the journal is the quality of the publication. We have certainly managed to lift the bar in terms of the page layout and design, language editing services, proofreading standards and compliance with international academic publishing standards.
We are open for suggestions and recommendations.

We also urge our collaborators of more than a decade to bear with us. In 2017, we are bound to be smoother and more effective in rapidly processing the latest research findings.

\section{Reference}

Rose, J.F.P., 2016, The well-tempered city: What modern science, ancient civilisations, and human nature teach us about the future of urban life, Harper Wave, New York. 